\title{
Iron absorption from a cereal-based meal containing cane sugar fortified with ascorbic acid
}

\author{
BY D. DERMAN, M. SAYERS, S. R. LYNCH, R. W. CHARLTON \\ AND T. H. BOTHWELL* \\ South African MRC Iron and Red Cell Metabolism Unit, Departments of Medicine and \\ Pharmacology, University of the Witwatersrand, Johannesburg, South Africa
}

\author{
AND FATIMA MAYET \\ Department of Medicine, University of Natal, Durban, South Africa
}

(Received 21 December 1976 - Accepted 24 January 1977)

1. The feasibility of improving iron nutrition by fortifying cane sugar with ascorbic acid was studied.

2. The absorption of Fe added to maize-meal porridge was measured in 116 volunteer multiparous Indian women using the radio-Fe erythrocyte utilization method. The meals were fed with and without tea or coffee and with and without varying amounts of ascorbic acid.

3. The mean absorption of Fe from maize-meal porridge was very low (3.8\%), being even further reduced $(2.1 \%)$ when tea was drunk with the meal.

4. The addition of 50 or $100 \mathrm{mg}$ ascorbic acid to maize-meal porridge caused approximately a 10-fold increase in Fe absorption. The increase was much less when tea was present, being 2-fold and 5-fold with 50 and $100 \mathrm{mg}$ ascorbic acid respectively. The inhibitory effect of tea on Fe absorption could, however, be overcome by giving larger doses of ascorbic acid ( 250 and $500 \mathrm{mg}$ ).

5. When contaminating $\mathrm{Fe}(2.5 \mathrm{mg})$ in the form of labelled rust $\left(\mathrm{Fe}_{2} \mathrm{O}_{3}\right)$ or ferric hydroxide was added to maize-meal porridge it was poorly absorbed (mean values were $0.01 \%$ and $1.5 \%$ respectively). The addition of $100 \mathrm{mg}$ ascorbic acid increased the mean $\mathrm{Fe}$ absorption rates to $0.5 \%$ and $6.7 \%$ with $\mathrm{Fe}_{2} \mathrm{O}_{3}$ and $\mathrm{Fe}(\mathrm{OH})_{3}$ respectively. $\mathrm{Fe}(\mathrm{OH})_{3}$ was found to be absorbed about half as well as the intrinsic Fe present in maize-meal porridge.

6. It is concluded that ascorbic acid is capable of improving $\mathrm{Fe}$ absorption from a cereal source. It can partially overcome the inhibitory effect of tea and might be expected to facilitate the absorption of at least some forms of $\mathrm{Fe}$ that may contaminate food.

Current methods aimed at promoting adequate iron nutrition in communities that are at risk of Fe deficiency have relied on the fortification of dietary staples with added Fe. However, the value of this approach has been questioned (Elwood, 1968), particularly since the demonstration that dietary non-haem-Fe is absorbed from a common pool (Björn-Rasmussen, Hallberg \& Walker, 1972; Cook, Layrisse, Martinez-Torres, Walker, Monsen \& Finch, 1972; Sayers, Lynch, Jacobs, Charlton, Bothwell, Walker \& Mayet, 1973). This means that Fe salts added to a particular diet are absorbed to the same extent as the nonhaem-Fe present in that diet. If, therefore, the diet consists predominantly of cereals such as wheat, maize and rice which have been shown to be extremely poor sources of Fe, the added Fe is equally poorly absorbed (Martinez-Torres \& Layrisse, 1973). Presumably the dietary factors that restrict the absorption of the intrinsic $\mathrm{Fe}$ in these foodstuffs have a similar effect on the added Fe. A number of inhibitory ligands have been identified, including phosphates (Hegsted, Finch \& Kinney, 1949; Chapman \& Campbell, 1957; Peters, Apt \& Ross, 1971) and tannates (Disler, Lynch, Charlton, Torrance, Bothwell, Walker \& Mayet, 1974; Disler, Lynch, Charlton, Bothwell, Walker \& Mayet, 1975). These considerations have led to the suggestion that a more rational approach to the correction of $\mathrm{Fe}$ deficiency would be to render the intrinsic dietary $\mathrm{Fe}$ more available by adding ligands

\footnotetext{
* For reprints.
} 
which promote Fe absorption, such as ascorbic acid (Sayers et al. 1973; Sayers, Lynch, Charlton, Bothwell, Walker \& Mayet, $1974 a, b$ ). While this approach would obviously be of limited value in situations where the dietary Fe content is low, some cereal-based diets consumed by Fe-deficient populations have been shown to contain apparently adequate quantities of $\mathrm{Fe}$. Not all this $\mathrm{Fe}$ is necessarily intrinsic to the food; for example, chemical assays of different Indian diets have consistently revealed Fe contents considerably in excess of those predicted from food tables (Ramalingaswami \& Patwardhan, 1949; Apte \& Iyengar, 1970; Soni \& Sharma, 1974). The contaminating Fe present in such diets must represent either soil contamination or Fe derived from cooking utensils. Whatever its source it is apparently very poorly absorbed, since Fe deficiency is prevalent in those areas.

The aims of the present study were threefold. First, basal values were obtained for the availability of the Fe present in maize-meal porridge, a common ingredient in the diet of South Africans of Indian descent, with emphasis on the extent to which absorption was further inhibited when tea or coffee was drunk during the meal which is the usual custom. Secondly the extent to which $\mathrm{Fe}$ absorption from such a diet could be enhanced by the addition of various quantities of ascorbic acid was determined. Finally the effect, if any, of ascorbic acid on the absorption of some common forms of contaminating Fe that could be present in a cereal diet was studied.

\section{EX PER I MENTA L}

Multiparous Indian housewives (116) took part in the study. They were aged between 21 and 71 years (mean 36 years). They belonged to a low socio-economic group and lived in a municipal housing complex at Chatsworth, near Durban. Previous studies have shown that Fe deficiency is common in this community (Mayet, Adams, Moodley, Kleber \& Cooper, 1972).

The meal was eaten on two consecutive mornings, its non-haem-Fe being extrinsically labelled on one occasion with $2.5 \mu \mathrm{Ci}{ }^{55} \mathrm{Fe}$ and on the other occasion with $2.5 \mu \mathrm{Ci}{ }^{59} \mathrm{Fe}$. $\mathrm{Fe}$ added in this way is absorbed to the same extent as the non-haem-Fe present in the meal (Cook et al. 1972). The effects of different concentrations of ascorbic acid $(0,50,100,250$ and $500 \mathrm{mg}$ ) and tea or coffee on the absorption of the Fe were compared. In other studies $\mathrm{Fe}$ was added to the meal in the form of either rust $\left(\mathrm{Fe}_{2} \mathrm{O}_{3}\right)$ or ferric hydroxide and its absorption measured. In addition, the relative absorptions of ${ }^{59} \mathrm{Fe}(\mathrm{OH})_{3}$ and ${ }^{55} \mathrm{FeCl}_{3}$ were compared when fed in the same meal.

\section{Preparation and administration of the meals}

Sufficient maize meal was weighed out to provide $40 \mathrm{~g}$ dry maize/subject and mixed with water $(1: 4, w / w)$. At the same time the radio-Fe, in some experiments in addition to the added $\mathrm{Fe}$, was mixed with a portion of the water-maize meal mixture to form a paste which was then thoroughly mixed with the remainder of the water-maize meal mixture before cooking for $20-25 \mathrm{~min}$ to $90-95^{\circ}$. The final weight of porridge eaten by each subject was approximately $150 \mathrm{~g}$. Tea was made by adding $5 \mathrm{~g}$ leaves (Pot o' Gold; O.K. Bazaars Ltd, Johannesburg) to a sufficient volume of water to provide $150 \mathrm{ml} / \mathrm{subject}$. Each cup of tea also contained $10 \mathrm{ml}$ milk. The tea was sweetened with cane sugar, according to each individual's taste. The preparation of the coffee was identical, except that $3 \mathrm{~g}$ ground coffee (Frisco Foods Corporation, Johannesburg) were used. Portions of cane sugar $(20 \mathrm{~g})$ were weighed separately for addition to the porridge. This cane sugar was prepared either free of ascorbic acid, or contained $50,100,250$ or $500 \mathrm{mg}$ ascorbic acid. The cane sugar was sprinkled over the porridge immediately before it was eaten.

In every study the meal was consumed after an overnight fast and no food or drink was allowed for $4 \mathrm{~h}$ after the test meal had been eaten. The same procedure was followed the 
next day, but the meal was labelled with the other Fe isotope. After a period of 2 weeks, blood samples were taken after an overnight fast for the determination of the concentrations of ${ }^{59} \mathrm{Fe}$ and ${ }^{55} \mathrm{Fe}$, haemoglobin, serum $\mathrm{Fe}$, unsaturated $\mathrm{Fe}$-binding capacity and serum ferritin. Each subject then drank a 'reference Fe salt' consisting of $50 \mathrm{ml}$ of a solution containing $30 \mathrm{mg}$ ascorbic acid and $3 \mathrm{mg} \mathrm{Fe}$ as ${ }^{59} \mathrm{FeSO}{ }_{4}, 7 \mathrm{H}_{2} \mathrm{O}\left(2.5 \mu \mathrm{Ci}{ }^{59} \mathrm{Fe}\right)$; no food or drink was allowed for the subsequent $4 \mathrm{~h}$ period. A further 2 weeks later, samples of blood were again obtained and the ${ }^{59} \mathrm{Fe}$ concentrations determined. The absorption of the $\mathrm{Fe}$ in the solution, which was calculated by difference, provided an index of each individual's absorbing capacity.

\section{Preparation of fortified cane sugar}

L(+)-ascorbic acid (analytical grade; BDH Chemicals Ltd, Poole, Dorset, UK) was added to $1 \mathrm{~kg}$ batches of commercial white cane sugar (Huletts Refineries Ltd, Durban) in the concentrations described previously. The supplementation was carried out by first dissolving the ascorbic acid in distilled water and then spraying the solution onto cane sugar dampened with water $(1 \mathrm{gm} / \mathrm{kg})$. The cane sugar was then dried under warm air. The results of previous studies (Disler, Lynch, Charlton, Bothwell et al. 1975) have indicated that it is possible to store cane sugar fortified in this way without altering consumer acceptability.

\section{Isotopic and chemical methods}

Duplicate blood samples $(10 \mathrm{ml})$ and duplicate portions of maize meal $(1-2 \mathrm{~g})$ and appropriate standards were prepared for differential radioactivity determination by the method of Katz, Zoukis, Hart \& Dern (1964). The quantities of ${ }^{55} \mathrm{Fe}$ and ${ }^{59} \mathrm{Fe}$ in the processed samples were determined using a liquid-scintillation system (Insta-Gel; Tri-Carb AAA Spectrometer Model no. 3375; Packard Instrument Co., Downers Grove, Illinois, USA) which automatically adjusted for quenching. The counting efficiency was $24 \%$ for ${ }^{55} \mathrm{Fe}$ and $42 \%$ for ${ }^{59} \mathrm{Fe}$ at optimal gain and window settings. The ${ }^{59} \mathrm{Fe}$ activity in the $4 \mathrm{ml}$ blood samples collected immediately before the 'reference Fe salt' was administered, and 2 weeks later, was assessed against suitable standards using a liquid-scintillation spectrometer (Auto-Gamma Tri-Carb Spectrometer Model no. 3001 ; Packard Instrument Co.). All values for absorption (\%) were calculated on the assumption that $100 \%$ of the absorbed radioactivity was present in the haemoglobin of circulating erythrocytes, and that the blood volume of each subject was $65 \mathrm{ml} / \mathrm{kg}$.

Serum Fe concentrations were measured by a modification (Bothwell \& Finch, 1962) of the method of Bothwell \& Mallett (1955) in which sulphonated bathophenanthroline was used as the colour reagent. The unsaturated Fe-binding capacity was determined by the method of Herbert, Gottlieb, Lau, Gevirtz, Sharney \& Wasserman (1967). The Fe content of digested samples of food was estimated by a modification (Bothwell \& Finch, 1962) of the method of Lorber (1927). The serum ferritin concentrations were measured by radioimmunoassay using the method of Miles, Lipschitz, Bieber \& Cook (1974). ${ }^{55} \mathrm{Fe}_{2} \mathrm{O}_{3}$ and ${ }^{59} \mathrm{Fe}(\mathrm{OH})_{3}$ were prepared by the methods described by Vogel (1960).

\section{Ethical considerations}

Written consent was obtained from all subjects after the nature of the investigation had been explained to them by an Indian social worker. Before starting the study approval was obtained from the Committee for Research on Human Subjects of the Faculty of Medicine, University of the Witwatersrand, Johannesburg. With regard to radiation exposure, it was calculated that if the entire test dose of radioisotope was retained, the total radiation averaged over 13 weeks would be approximately $20 \%$ and $0.2 \%$ of the permissible wholebody burden for continuous exposure to ${ }^{59} \mathrm{Fe}$ and ${ }^{55} \mathrm{Fe}$ respectively (International Commission for Radiation Protection, 1960). 


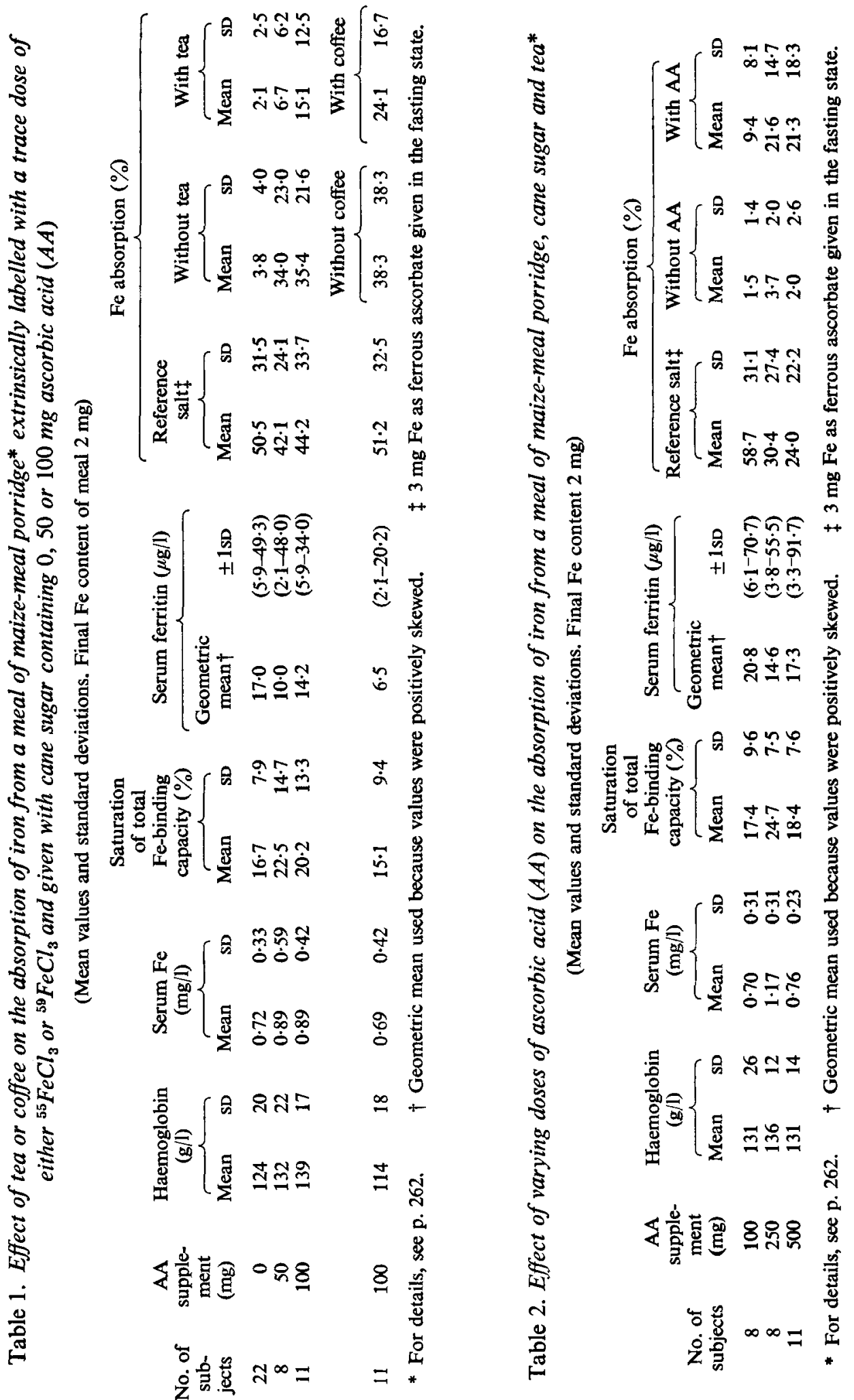




\section{RESULTS}

\section{Effect of tea or coffee on absorption of Fe from maize-meal porridge}

In the first study the maize-meal porridge sweetened with cane sugar was consumed by twenty-two subjects, with a cup of tea on one morning and on the second morning without a cup of tea. The purpose of the study was twofold; first to establish basal values for absorption of $\mathrm{Fe}$ from the test meal and secondly to determine to what extent tea interfered with absorption. The mean $\mathrm{Fe}$ absorption was $3.8 \%$ as compared with $2.1 \%$ when a cup of tea was drunk with the porridge (Table 1 ); the difference was highly significant $(t 2.96, P<0.01)$. In two further studies on groups of eight and eleven subjects respectively the same procedure was used except that cane sugar fortified with either 50 or $100 \mathrm{mg}$ ascorbic acid was added to the meal on both occasions. As was anticipated from results of previous studies (Sayers et al. 1973; Sayers et al. 1974a, b) ascorbic acid at both dosage levels caused approximately a ninefold increase in the absorption of Fe from maize-meal porridge. However, this effect was markedly reduced when tea was drunk with the meal. Tea caused a decrease in the mean Fe absorption from 34.0 to $6.7 \%(t 5.76, P<0.001)$ when $50 \mathrm{mg}$ ascorbic acid was present and from 35.4 to $15.1 \%(t 5.85, P<0.0002)$ when the dosage was $100 \mathrm{mg}$ ascorbic acid. In a final study (eleven subjects) in which $100 \mathrm{mg}$ ascorbic acid was present in the test meal, coffee was drunk on one morning. Its effect was similar to that produced by tea, but was less marked; the mean Fe absorption was reduced from 38.3 to $24.1 \%(t 4.30, P<0.002)$. The validity of a direct comparison of results obtained in these different groups of women was strengthened by the finding that the mean values for $\mathrm{Fe}$ absorption (\%) from a 'reference Fe salt' were very similar in the four groups studied (50.5, 42.1, 44.2 and $51 \cdot 2$ respectively).

\section{Effects of increasing doses of ascorbic acid on Fe absorption from a meal of maize-meal porridge and tea}

The results of the previous studies indicated that the enhancing effect of ascorbic acid on $\mathrm{Fe}$ absorption from maize-meal porridge was partially prevented when tea was taken with the meal. It was therefore decided to determine the extent to which this effect could be overcome by increasing quantities of ascorbic acid.

In the first experiment eight volunteers were given a breakfast of maize-meal porridge and tea. On the second day the cane sugar used to sweeten the porridge contained $100 \mathrm{mg}$ ascorbic acid. The presence of ascorbic acid was associated with an increase in mean Fe absorption from 1.5 to $9.4 \%(t 3.27, P<0.02)$ (Table 2$)$. In a second experiment a similar study was carried out on a further eight subjects, using $250 \mathrm{mg}$ ascorbic acid, and the mean increase in mean $\mathrm{Fe}$ absorption was from 3.7 to $21.6 \%(t 3.8, P<0.01)$. In a final study on eleven volunteers, the amount of ascorbic acid was increased further to $500 \mathrm{mg}$. The ascorbic acid caused an increase in mean Fe absorption from 2.0 to $21.3 \%(t 3.92, P<0.005)$.

Direct comparisons between these results were complicated by the fact that the mean $\mathrm{Fe}$ absorption from 'reference Fe salt' was considerably higher in the first group than it was in the other two groups $(58.7 \%$ as compared with $30.4 \%$ and $24 \%$ respectively), indicating that the subjects in the first group were more avid for Fe. It was nevertheless possible to conclude that the enhancement of $\mathrm{Fe}$ absorption produced by ascorbic acid was greater with the very large doses ( 250 and $500 \mathrm{mg}$ ).

\section{Effect of ascorbic acid on the absorption of $\mathrm{Fe}_{2} \mathrm{O}_{3}$ and $\mathrm{Fe}(\mathrm{OH})_{3}$ from a maize-meal porridge meal}

In the first experiment the standard maize-meal porridge contained $2.5 \mathrm{mg} \mathrm{Fe}$ as $\mathrm{Fe}_{2} \mathrm{O}_{3}$ and was eaten by twelve subjects. The cane sugar added to the porridge was fortified on the 


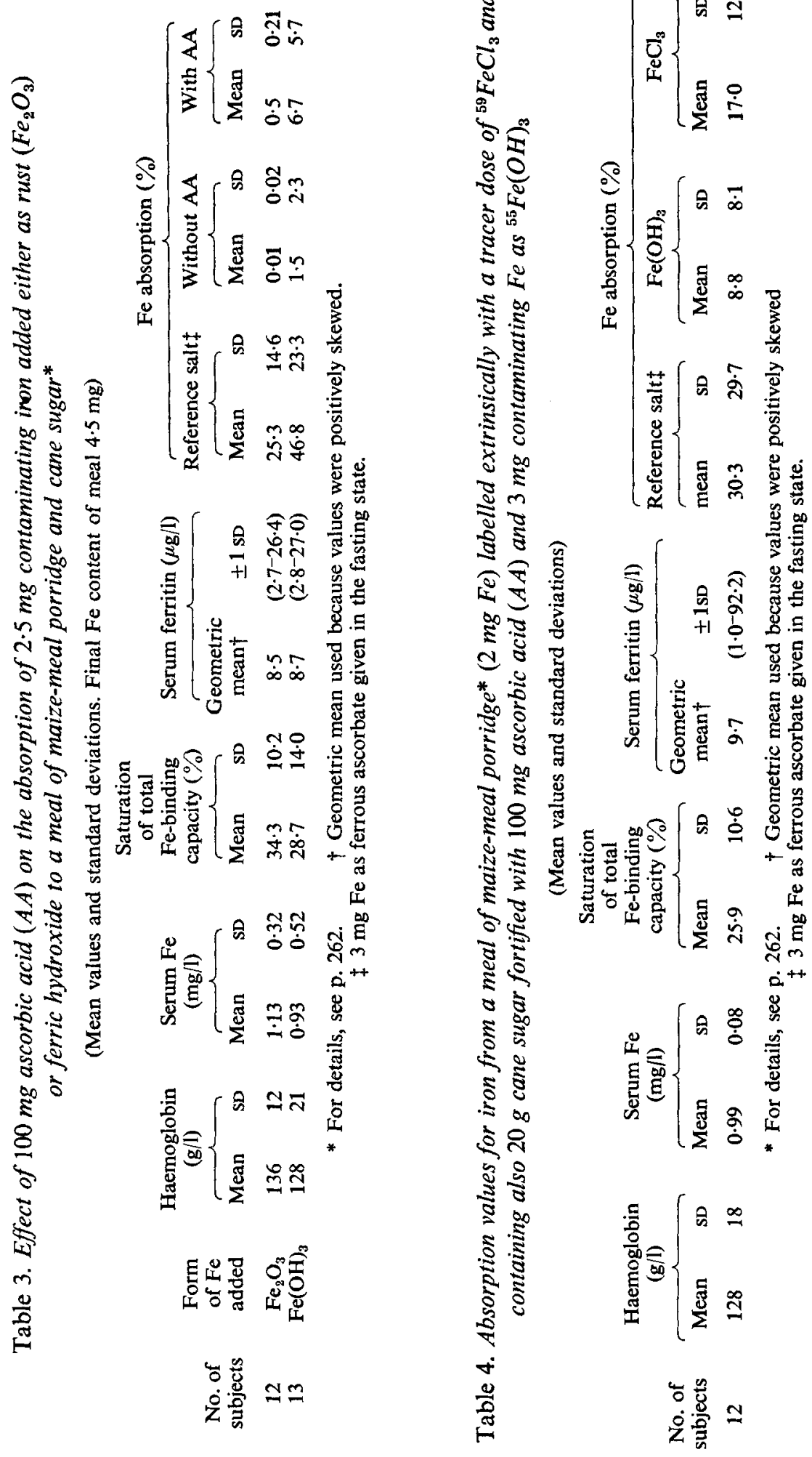


one occasion with $100 \mathrm{mg}$ ascorbic acid. The mean absorption of the added Fe increased from 0.01 to $0.5 \%$ when ascorbic acid was present (Table 3), but although the difference was statistically significant $(t 5.62, P<0.001)$ the amounts were too small to be of any biological significance. While it was noted that the mean reference absorption of this group was relatively low $(25.3 \%$ ), absorption of the $\mathrm{Fe}$ in the meal was less than $1 \%$ even in those individuals with the highest 'reference $\mathrm{Fe}$ ' absorption rates. Thirteen volunteers took part in the second experiment which was identical to the first except that $\mathrm{Fe}(\mathrm{OH})_{3}$ was substituted for the $\mathrm{Fe}_{2} \mathrm{O}_{3}$. The mean basal absorption was $1.5 \%$, while the addition of $100 \mathrm{mg}$ ascorbic acid increased $\mathrm{Fe}$ absorption to $6.7 \%(t 4.71, P<0.001)$. The mean absorption of the 'reference Fe salt' was $46.8 \%$.

While the results obtained in the second experiment suggested that Fe present in a meal in the form of $\mathrm{Fe}(\mathrm{OH})_{3}$ might be partly available for absorption under certain circumstances, the values obtained for absorption in the presence of ascorbic acid appeared to be lower than those for the non-haem-Fe in maize-meal porridge obtained in previous studies (Sayers $e t$ al. 1973; Sayers et al. $1974 a, b)$. The absorption of $\mathrm{Fe}$ from ${ }^{59} \mathrm{Fe}(\mathrm{OH})_{3}$ added to the porridge was therefore compared in twelve subjects with that of the food $\mathrm{Fe}$ extrinsically labelled with a tracer dose of ${ }^{55} \mathrm{FeCl}_{3}$. Ascorbic acid $(100 \mathrm{mg})$ was present as described previously. The mean absorption of the non-haem-Fe in the maize-meal was $17.0 \%$ as compared with a value of $8.8 \%$ for the $\mathrm{Fe}$ given as $\mathrm{Fe}(\mathrm{OH})_{3}(t 5.33, P<0.001)$ (Table 4).

\section{DISCUSSION}

Fe-deficiency anaemia has been shown to be common in the population from which the Indian women who volunteered for the absorption studies was drawn (Mayet et al. 1972). The current findings confirmed this: in thirty-nine of the 116 subjects Fe-deficient erythropoiesis was suggested by the finding of values for saturation of total Fe-binding capacity ( $\%)$ of 15 or less and thirty subjects were anaemic on the basis of a haemoglobin concentration of less than $120 \mathrm{~g} / \mathrm{l}$ (Committee on Iron Deficiency, 1968). The results also include geometric mean values for ferritin for each group The geometric mean was calculated as it is a better indication of central tendency for positively-skewed values. In none of the groups did the mean value approach the normal value of $35 \mu \mathrm{g} / 1$ (Jacobs, Miller, Worwood, Beamish \& Wardrop, 1975). In addition, the over-all mean absorption of $3 \mathrm{mg} F e$ as ferrous ascorbate was $41 \cdot 2 \%$ (SD $28 \cdot 1$ ). The avidity with which this 'reference' salt was absorbed further characterized the group as being Fe deficient (Kuhn, Monsen, Cook \& Finch, 1968). This background of $\mathrm{Fe}$ deficiency gave added relevance to the in vivo $\mathrm{Fe}$ absorption findings, since it is target populations such as this to which Fe-fortification programmes will be directed.

Part of the explanation for the group's Fe deficiency may be the low Fe content of their predominantly cereal-based diets. In support of this was the observation that their typical breakfast meal of maize-meal porridge, cane sugar and tea or coffee, from which absorption was measured in the present study, contained only $2.0 \mathrm{mg}$ Fe. The problem is further compounded by the fact that the $\mathrm{Fe}$ in the maize meal is poorly absorbed, even by Fe-deficient subjects. The mean Fe absorption from the maize-meal porridge was only $3.8,1.5$ and $3.7 \%$ respectively in three different studies, and these low absorption rates were reduced by half when tea was drunk with the meal. Thus the commonly consumed breakfast of maize-meal porridge, cane sugar and tea permits the absorption of less than $0.05 \mathrm{mg} F e$.

In previous studies we have shown that when ascorbic acid is added to porridge it potentiates the absorption of the Fe present in maize meal (Sayers et al. 1973). As can be seen in Table 1 this observation was confirmed when 50 or $100 \mathrm{mg}$ ascorbic acid caused a ninefold increase in absorption. When tea was present, the effect was less marked but still significant; 
the mean absorption was approximately $0.13 \mathrm{mg} \mathrm{Fe}$ with $50 \mathrm{mg}$ ascorbic acid and $0.3 \mathrm{mg} \mathrm{Fe}$ with $100 \mathrm{mg}$ ascorbic acid.

On the strength of these findings, fortification of the diet with ascorbic acid alone deserves consideration as a rational means of improving $\mathrm{Fe}$ nutrition. In the past the accent has been laid on adding $\mathrm{Fe}$ to the diet, but this has not proved effective, especially with predominantly cereal diets. It might be argued that optimal results would be obtained if both $\mathrm{Fe}$ and ascorbic acid were added but previous work has shown that there are many practical problems in achieving this end. For example, if cooking salt (sodium chloride) is used as a carrier it discolours when an Fe salt and ascorbic acid are added (Sayers et al. 1974), while cane sugar fortified in this way discolours tea by precipitating the tannins (Disler et al. 1974; 1975).

Since dietary fortification with ascorbic acid alone may be an acceptable alternative to $\mathrm{Fe}$ fortification in the correction of Fe deficiency, it should be emphasized that this approach could have wider implications. As has been pointed out, many Fe-deficient groups consume diets with $\mathrm{Fe}$ contents in excess of those suggested by food tables. While there has been little work aimed at identifying the chemical nature of this extraneous $\mathrm{Fe}$, two likely compounds are $\mathrm{Fe}_{2} \mathrm{O}_{3}$ as rust derived from cooking utensils, and $\mathrm{Fe}(\mathrm{OH})_{3}$, which belongs to the group of $\mathrm{Fe}$ compounds most commonly found in soil and unpurified water sources (Whittemore \& Langmuir, 1975). The present study has shown that ascorbic acid does not enhance the absorption of $\mathrm{Fe}_{2} \mathrm{O}_{3}$, but there was a significant effect on the absorption of $\mathrm{Fe}(\mathrm{OH})_{3}$ (Table 3). This finding may have considerable relevance to diets with a high content of extraneous $\mathrm{Fe}$. In passing, it was interesting to note that $\mathrm{Fe}(\mathrm{OH})_{3}$, though available to some extent for absorption when ascorbic acid was present, did not form a 'common pool' with the non-haem-Fe in the meal. Isotopic exchange was incomplete and the $\mathrm{Fe}$ in $\mathrm{Fe}(\mathrm{OH})_{3}$ was only about half as well absorbed as was the other non-haem-Fe in the meal.

Economic considerations are obviously important in determining the feasibility of a fortification programme. If one assumes that each individual was exposed to an additional $100 \mathrm{mg}$ ascorbic acid/d then the cost on a per capita per year basis would be only about 30 cents.

This work was supported by grants from the Atomic Energy Board, South Africa and the South African Sugar Association. The authors are indebted to Mrs Shirley Lichtigfeld and Miss Fawzia Khan for their invaluable assistance.

\section{REFEREN CES}

Apte, S. V. \& Iyengar, L. (1970). Am. J. clin. Nutr, 23, 73.

Björn-Rasmussen, E., Hallberg, L. \& Walker, R. B. (1972). Am. J. clin. Nutr. 25, 317.

Bothwell, T. H. \& Finch, C. A. (1962). Iron Metabolism, 1st ed., pp. 18, 26. London: J. \& A. Churchill. Bothwell, T. H. \& Mallett, B. (1955). Biochem. J. 59, 599.

Chapman, D. G. \& Campbell, J. A. (1957). Br. J. Nutr. 11, 127.

Committee on Iron Deficiency (1968). J. Am. med. Ass. 203, 407.

Cook, J. D., Layrisse, M., Martinez-Torres, C., Walker, R., Monsen, E. \& Finch, C. A. (1972). J. clin. Invest. 51, 805 .

Disler, P. B., Lynch, S. R., Charlton, R. W., Bothwell, T. H., Walker, R. B. \& Mayet, F. (1975). Br. J. Nutr. 34, 141.

Disler, P. B., Lynch, S. R., Charlton, R. W., Torrance, J. D., Bothwell, T. H., Walker, R. B. \& Mayet, F. (1974). Gut 16, 193.

Elwood, P. C. (1968). Rep. Publ. Hlth med. Supj., Lond. no. 117.

Hegsted, D. M., Finch, C. A. \& Kinney, T. D. (1949). J. Exp. Med. 90, 147.

Herbert, V., Gottlieb, C. W., Lau, K. S., Gevirtz, N. R., Sharney, L. \& Wasserman, L. R. (1967). J. nucl. Med. 8, 529.

International Commission for Radiation Protection (1960). Report of Committee II on Permissible Dose of Internal Radiation 1959. I.C.R.P. Publication no. 2. Oxford: Pergamon Press.

Jacobs, A., Miller, F., Worwood, M., Beamish, M. R. \& Wardrop, C. A. (1972). Br. med. J. 4, 206.

Katz, J. H., Zoukis, M., Hart, W. L. \& Dern, R. J. (1964). J. Lab. clin. Med. 63, 885. 
Kuhn, 1. N., Monsen, E. R., Cook, J. D. \& Finch, C. A. (1968). J. Lab. clin. Med. 71, 715.

Lorber, L. (1927). Biochem. Z. 181, 391.

Martinez-Torres, C. \& Layrisse, M. (1973). Clin. Haemat. 2, 339.

Mayet, F. G. H., Adams, E. B., Moodley, T., Kleber, E. E. \& Cooper, S. K. (1972). S. Afr. med. J. 46, I427.

Miles, L. E. M., Lipschitz, D. A., Bieber, C. P. \& Cook, J. P. (1974). Analyt. Biochem. 61, 209.

Peters, T., Apt., L. \& Ross, J. F. (1971). Gastroenterology 61, 315.

Ramalingaswami, R. \& Patwardhan, V. N. (1949). Indian J. med. Res. 37, 51.

Sayers, M. H., Lynch, S. R., Charlton, R. W., Bothwell, T. H., Walker, R. B. \& Mayet, F. (1974a). Br. J. Nutr. 31, 367.

Sayers, M. H., Lynch, S. R., Charlton, R. W., Bothwell, T. H., Walker, R. B. \& Mayet, F. (1974b). Br. J. Haemat. 28, 483.

Sayers, M. H., Lynch, S. R., Jacobs, P., Charlton, R. W., Bothwell, T. H., Walker, R. B. \& Mayet, F. (1973). Br. J. Haemat. 24, 209.

Soni, B. L. \& Sharma, D. C. (1974). Am. J. clin. Nutr. 27, 5.

Vogel, A. I. (1960). Quantitative Inorganic Analysis, 2nd ed., p. 407. London: Longmans.

Whittemore, D. O. \& Langmuir, D. (1975). Ground Water 13, 360. 